\title{
Dissecting the cost of insecticide resistance genes during the overwintering period of the mosquito Culex pipiens
}

\author{
ÉLODIE GAZAVE, CHRISTINE CHEVILLON, THOMAS LENORMAND, MAÏTÉ \\ MAROUINE \& MICHEL RAYMOND* \\ Genetics of Adaptation, Laboratoire Génétique et Environment, Institut der Sciences de l'Evolution (UMR CNRS \\ 5554), Université de Montpellier II (c. c. 065) F-34095 Montpellier cedex 05, France
}

\begin{abstract}
In several insects, there appears to be a high fitness cost associated with insecticide resistance genes during the overwintering period. In order to understand when and how this cost operates, all mosquitoes entering a natural cave for overwintering were regularly sampled, and their resistance genes at two loci (Ester and Ace.1) were individually identified. During the main period of entry (October and November), susceptible mosquitoes were first observed, followed by resistant ones, this trend being similar for both loci. This observation is best explained by a migration phenomenon, northern and more susceptible populations starting to overwinter first, followed by southern and more resistant ones. During the remaining part of the winter (December-March), mosquitoes entering the cave were still caught and they probably corresponded to individuals leaving a former overwintering site in search of a more suitable one. A lower overall frequency of resistant phenotypes was found in the second part of the winter at Ester, suggesting that a large fitness cost $(42 \%)$ had operated. A decreasing frequency of resistant phenotypes was also found at Ace.1, indicating a large survival cost of resistant mosquitoes $\left(7 \%\right.$ for the homozygote $\left.A c e .1^{R}\right)$ in their former overwintering site. These results are discussed in the light of the local evolution of these resistance genes in southern France.
\end{abstract}

Keywords: adaptation, cost, hibernation, insecticide resistance, migration.

\section{Introduction}

Insecticide resistance genes are now common in insect genomes due to the recent and frequent use of chemicals by man. Resistance genes alter some components of the basic physiology and interfere with fitness-related life history traits, thus defining a fitness cost (e.g. Georghiou, 1972; Uyenoyama, 1986; Roush \& McKenzie, 1987). To study the process of adaptation at the gene level, it is important to understand how this fitness cost effect operates and how it could evolve (Guillemaud et al., 1998; Davies et al., 1996; Orr, 1998).

Resistance to organophosphates (OPs) in the mosquito Culex pipiens is a convenient model for investigating fitness cost of resistance genes directly in natural populations. Two main loci are responsible for OP resistance, corresponding to different resistance mechanisms. The first locus, Ace.l, codes for an acetylcholinesterase (AChE1), the OP target (Bourguet et al., 1996c; Malcolm et al., 1998). There are three alleles at this locus: Ace. $1^{R}$ which codes for an insensitive AChE1,

*Correspondence. E-mail: raymond@isem.univ-montp2.fr
Ace. $1^{S}$ which codes for a sensitive AChE1, and Ace. $1^{R S}$ which corresponds to a duplication of Ace.l that codes for both enzymes (Raymond et al., 1986; Bourguet et al., 1996a; Lenormand et al., 1998a). The second 'locus' corresponds to two closely linked loci Est-3 and Est-2 coding for esterases $\mathrm{A}$ and $\mathrm{B}$, respectively (de Stordeur, 1976; Pasteur et al., 1981a,b). Resistance alleles at these two esterase loci induce an overproduction of esterase, due to either gene amplification or gene regulation (Rooker et al., 1996). Because of their close proximity (2-6 kb of DNA between Est-3 and Est-2), resistance alleles are often coamplified as a single unit, explaining the complete association of resistance alleles at both loci (Rooker et al., 1996; Guillemaud et al., 1997). This justifies considering them as a single 'super locus', which will be designated subsequently as Ester. The nomenclature used in this paper is indicated in Table 1. In southern France, three resistance Ester alleles have been identified. Ester ${ }^{l}$ corresponds to an increased expression of esterase A1, Ester ${ }^{2}$ and Ester ${ }^{4}$ correspond to an increased expression of both esterases $\mathrm{A}$ and $\mathrm{B}$ (A2-B2 and A4-B4, respectively). 
Table 1 Nomenclature used for phenotypes and genotypes of Culex pipiens

\begin{tabular}{|c|c|c|c|c|}
\hline \multicolumn{3}{|c|}{ Phenotypes } & \multicolumn{2}{|r|}{ Corresponding genotypes } \\
\hline & Coding & Class & Homozygote & Heterozygote \\
\hline \multicolumn{5}{|l|}{ Overproduced esterases } \\
\hline None & [0] & $\{\mathrm{O}\}$ & Ester $^{0}$ Ester $^{0}$ & - \\
\hline A1 & [1] & $\{\mathrm{E}\}$ & Ester $^{I}$ Ester $^{I}$ & Ester $^{I}$ Ester $^{O}$ \\
\hline $\mathrm{A} 2-\mathrm{B} 2$ & [2] & $\{\mathrm{E}\}$ & Ester $^{2}$ Ester $^{2}$ & Ester $^{2}$ Ester $^{0}$ \\
\hline A4-B4 & [4] & $\{\mathrm{E}\}$ & Ester $^{4}$ Ester $^{4}$ & Ester $^{4}$ Ester $^{0}$ \\
\hline $\mathrm{A} 1$ and $\mathrm{A} 2-\mathrm{B} 2$ & [12] & $\{\mathrm{E}\}$ & - & Ester $^{1}$ Ester $^{2}$ \\
\hline A1 and A4-B4 & [14] & $\{\mathrm{E}\}$ & - & Ester $^{1}$ Ester $^{4}$ \\
\hline $\mathrm{A} 2-\mathrm{B} 2$ and $\mathrm{A} 4-\mathrm{B} 4$ & [24] & $\{\mathrm{E}\}$ & - & Ester $^{2}$ Ester $^{4}$ \\
\hline \multicolumn{5}{|l|}{ AChE1 } \\
\hline Susceptible & {$[\mathrm{SS}]$} & $\{\mathrm{S}\}$ & Ace. $1^{S}$ Ace. $1^{S}$ & - \\
\hline Susceptible \& resistant & {$[\mathrm{RS}]$} & $\{\mathbf{R}\}$ & Ace. $1^{R S}$ Ace. $1^{R S}$ & Ace. $1^{R}$ Ace. $1^{S} ;$ Ace. $1^{R S}$ Ace. $1^{S} ;$ Ace. $1^{R S}$ Ace. $1^{R}$ \\
\hline Resistant & {$[\mathrm{RR}]$} & $\{\mathbf{R}\}$ & Ace. $1^{R}$ Ace. $1^{R}$ & - \\
\hline
\end{tabular}

'Coding' indicates the simplified codes for each phenotype corresponding to the genotypes (either homozygote or heterozygote) indicated in the last two columns. 'Phenotypes' corresponds to the electrophoretic phenotype for the Ester locus or to the AChE1 type (susceptible or resistant) detected by the TPP test for the Ace. 1 locus (see text for details). 'Class' groups genotypes with at least one resistance allele. $\{\mathrm{E}\} /\{\mathrm{O}\}$ stands for the presence/absence of at least one overproduced esterase and $\{\mathbf{R}\} /\{\mathrm{S}\}$ for the presence/absence of at least one insensitive AChE1.

The winter period of temperate areas seems a good time to study the cost of insecticide resistance genes. This is because overwintering is probably a very challenging situation. In the Australian sheep blowfly Lucilia cuprina, individuals possessing the diazinon resistance gene Ropl experience a higher mortality during winter than susceptible flies, and their frequency drops by $80 \%$ (McKenzie, 1994). Similar decreases of resistance genes are found in populations of the aphid Myzus persicae (Foster et al., 1996, 1997, 2000), and in the mosquito Culex pipiens (Chevillon et al., 1997; Lenormand et al., 1999; Lenormand \& Raymond, 2000). In all these cases, the proximal cause of the lower survival associated with insecticide resistance genes is poorly known, although in $M$. persicae resistant forms have higher mortality during colder, wetter and windier weather, caused by a direct mortality through freezing and/or an indirect mortality through maladaptive behaviour (Foster et al., 2000).

To understand better the proximal causes of this overwintering fitness cost, this study has focused at the beginning of the overwintering period. Are resistant and susceptible mosquitoes starting the overwintering period at the same time? If not, could this difference be interpreted in terms of a fitness cost? To answer this question, all mosquitoes starting their overwintering period in a particular cave were caught, and all known resistance genes at both Ester and Ace.l loci were identified in each individual. This cave is located near Montpellier in an insecticide treated area (which represents a band of $\approx 20 \mathrm{~km}$ along the cost), at a few kilometres from an untreated area, i.e. a place where the insecticide resistance genes display an intermediate frequency. Results at both resistance loci were considered separately, as locus-specific effects are more likely to represent a fitness cost due to the very different resistance mechanisms involved.

\section{Materials and methods}

\section{Mosquito sampling}

Mosquitoes were collected in a small natural cave ('Grotte du zoo') within the city of Montpellier, southern France. Nearly all the cave walls were accessible for sampling, and during each sampling session, it was intended to collect all mosquitoes in the cave. The first sampling session occurred on 15th October 1997, and was repeated every other day until 8th December (except 2nd November), then every four days until 24th December, and every 6 days until 13th March 1998. All sampled mosquitoes were identified to species under a microscope, and Culex pipiens were deep frozen for further analyses. Temperatures inside (in the middle the cave, near one wall) and outside (in a shaded area close to the entrance) were automatically recorded each hour during the experiment, using a 'Testostor' temperature probe (Testo, Paris, France). 


\section{Mosquito analyses}

Each mosquito was cut into two parts. The thorax and abdomen were used to detect the presence of overproduced esterases using starch-gel electrophoresis (TME 7.4 buffer, Pasteur et al., 1988). This method did not allow the characterization of genotypes, because heterozygotes (overproduced esterase/non-overproduced esterase) could not be discriminated from homozygotes for alleles encoding overproduced esterase. As a consequence, only seven phenotypes could be identified (see Table 1): three with only one overproduced esterase ([1], [2] and [4]), three with two overproduced esterases ([12], [24] and [14]), and one with none ([0]). The head was used to detect the presence of an insensitive AChE1 (acetylcholinesterase) using the TPP test (Bourguet et al., 1996b). This test characterizes individuals displaying sensitive, resistant or both types of acetylcholinesterase. Thus, individuals carrying a duplicated Ace. $1^{R S}$ allele and standard heterozygotes cannot be discriminated. Finally, when considering both loci, only 21 classes of individuals could be identified among the 60 possible genotypes. Table 1 indicates the correspondence between each genotype and its simplified code (parentheses) as well as the corresponding phenotype [brackets]. In addition, a phenotypic class for individuals that carry at least one resistance allele has been defined at each locus \{curly brackets\}. To characterize individuals at both loci, codes are in the order Ace.l, Ester, separated by a comma, and with the corresponding brackets. For example [RS, 4] corresponds to individuals that have an [RS] phenotype for the Ace.1 locus and a [4] phenotype at the Ester locus.

\section{Statistics}

'Heterozygote' excesses at the Ace.l (assuming that only Ace. $I^{R}$ and Ace. $I^{S}$ were segregating) locus were tested using an exact U-score test (Rousset \& Raymond, 1995). Departure from Hardy-Weinberg was measured using the $F_{\text {IS }}$ estimator of Weir \& Cockerham (1984). Independence of rows and columns in an $\mathrm{R} \times \mathrm{C}$ contingency table was tested using a Fisher exact test (Fisher, 1935). An unbiased estimate of the $P$-value was performed using the STRUC program (Raymond \& Rousset, 1995).

The variation in resistance gene frequencies according to the date of capture was tested using a logistic regression. Whenever present, overdispersion was corrected according to Crawley (1993). Relative rate of entrance associated with Ace.l phenotypes ([SS], [RS] and $[R R])$ were estimated by a log-linear model with Poisson error described by Manly (1985), using [SS] as the reference phenotype. Phenotypic counts were fitted first by two factors (PHENO, identifying the three phenotypes, the second factor identifying the rank of each sample), and then the interaction PHENO.DATE was introduced, where the DATE variable represents the day of sampling (Manly, 1985; Crawley, 1993). In this model, the regression slopes associated with resistant phenotypes ([RS] or $[R R]$ ) estimate their daily rate of entrance relative to [SS] mosquitoes. All these computations were performed with GLIM version 4 (Baker, 1987).

The survival cost $(s)$ associated with $\{\mathrm{E}\}$ mosquitoes between two sampling dates was estimated, conjointly to frequencies of $\{E\}$ mosquitoes, using maximum likelihood techniques. The MLE of $s$ is given by:

$\hat{s}=\left(n_{1} N_{2} \quad n_{2} N_{1}\right) /\left[\left(\begin{array}{ll}n_{1} & N_{1}\end{array}\right) n_{2}\right]$,

where $n_{1}$ and $n_{2}$ are the number of $\{\mathrm{E}\}$ mosquitoes at times 1 and 2, respectively, and $N_{1}$ and $N_{2}$ the total sample size at times 1 and 2, respectively.

\section{Results}

\section{Dynamics of the entry of mosquitoes into the cave}

A total of 1562 culicids were captured between 15th October 1997 and 13th March 1998, including 1388 Culex pipiens, 127 Culex hortensis, 43 Anopheles maculipennis and four Culiseta annulata. For C. pipiens, only three males were found (caught on 14th, 16th and 26th November). The distribution of the $C$. pipiens females captured through time is presented in Fig. 1A. Most mosquitoes were caught at the beginning of the sampling period: $29 \%$ were caught by the 9 th day (i.e. $23 \mathrm{rd}$ October), $44 \%$ by the 17 th day (31st October) and $92 \%$ by the 49 th day (2nd December). The remaining $8 \%$ were caught between the 51st and 144th days (between 4th December 1997 and 7th March 1998). Two main periods could thus be defined based on the dynamics of mosquito entry, hereafter referred to as $\mathrm{P} 1$ and $\mathrm{P} 2$. P1 corresponds to the first 50 sampling days (i.e. from 15 th October to 3rd December) during which mosquitoes massively enter into the cave with an average rate of 26 mosquitoes/day, and mean daily temperatures are moderate (inside: $12.8^{\circ} \mathrm{C}$; outside: $11.4^{\circ} \mathrm{C}$, Fig. 1B). P2 is a 3 -month period (from 4th December to 7th March) during which the entry rate is uniformly low, at an average of less than 1 mosquito/day, and mean daily temperatures are relatively low (inside: $8.9^{\circ} \mathrm{C}$; outside: $6.3^{\circ} \mathrm{C}$, Fig. 1B).

\section{Insecticide resistance genes}

A total of 1158 mosquitoes were analysed (i.e. $83.4 \%$ of the whole $C$. pipiens sample). For the Ester locus, results are available for 1125 mosquitoes: 330 were without

(C) The Genetics Society of Great Britain, Heredity, 87, 441-448. 
A

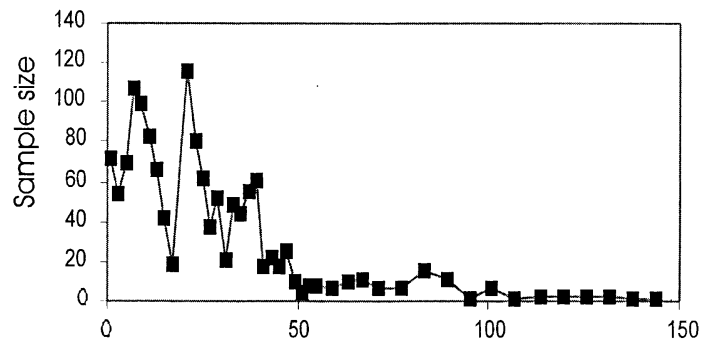

B
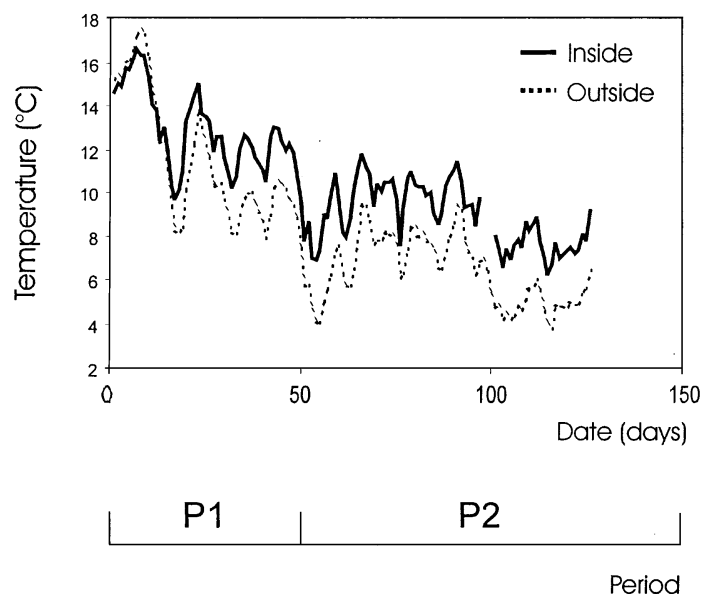

Fig. 1 Demography and variation in temperature during winter 1997/98. A, Number of Culex pipiens caught during each sampling session. B, Mean daily temperature, inside and outside the cave. The two sampling periods (P1 and $\mathrm{P} 2$ ) are indicated.

overproduced esterase (phenotype [0]), 714 with only one overproduced esterase $(619,63$ and 32 with phenotypes [4], [1] and [2], respectively), and 81 with two overproduced esterase $(3,61$ and 17 with phenotypes [21], [14] and [24], respectively). As Ester ${ }^{0}$ was recessive to all other alleles, genotypes of mosquitoes displaying only one overproduced esterase (corresponding to phenotypes [1], [2] or [4]) cannot be known (e.g. phenotype [1] could correspond to genotype Ester ${ }^{1} /$ Ester $^{0}$ or Ester ${ }^{1} /$ Ester ${ }^{l}$ ).

The various phenotypes did not randomly enter the cave through time (Fig. 2A). During P1, mosquitoes lacking overproduced esterases ([0]) significantly $(P=0.02)$ decreased in frequency, while the frequency of [4] mosquitoes significantly $(P=0.031)$ increased. These $P$-values are lower $(P=0.009$ and $P=0.023$, respectively) when the last sample of $\mathrm{P} 1$ is removed, i.e. at a time when trends were changing, suggesting that the actual definition of $\mathrm{P} 1$ and $\mathrm{P} 2$ is conservative. During $\mathrm{P} 2$, no trend is apparent, either for the other phenotypes which were at a low frequency, or for all phenotypes (Table 2, Fig. 2A). Overall, mosquitoes lacking overproduced esterases were at a lower frequency in $\mathrm{P} 1$
A

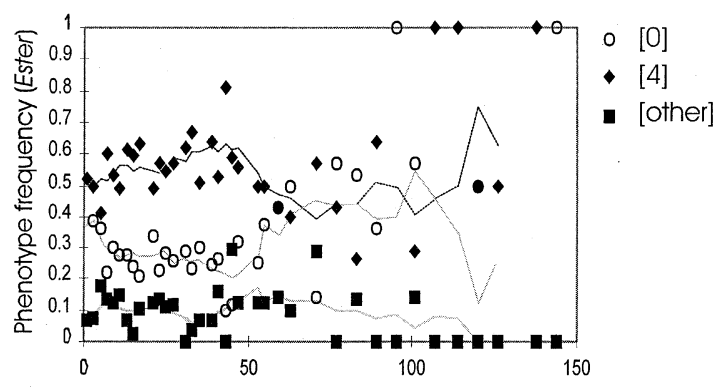

B

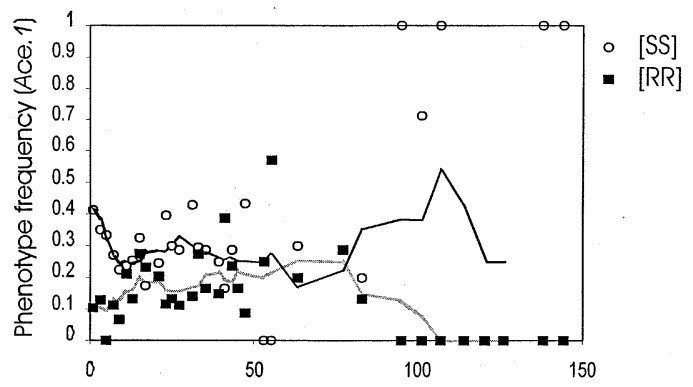

C

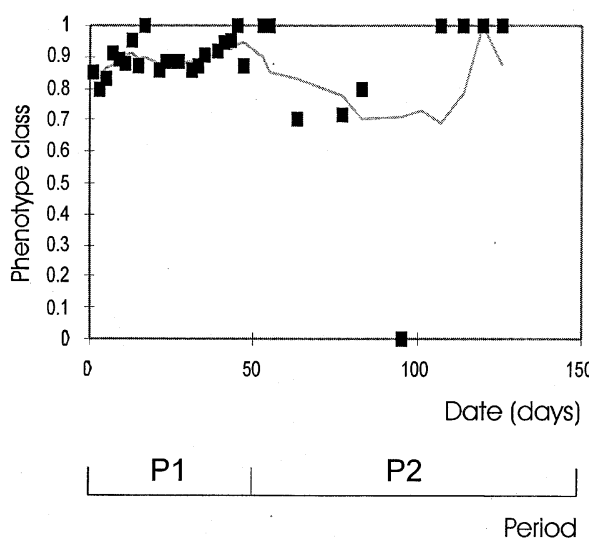

Fig. 2 Variation of resistance phenotype frequencies in Culex pipiens during winter 1997/98. A, variation of some Ester phenotypes; B, of Ace.1 phenotypes; and C, of the double resistant phenotype $\{\mathrm{R}, \mathrm{E}\}$. The dotted lines indicate variation tendencies smoothed over five consecutive points. The two sampling periods ( $\mathrm{P} 1$ and $\mathrm{P} 2)$ are indicated. Phenotype nomenclature is indicated in Table 1.

(0.28) than in P2 $(0.41)(2 \times 2$ Fisher exact test, $P=0.014)$. This variation corresponds to a relative survival cost of $\{E\}$ mosquitoes of $42 \%$ between $P 1$ and P2.

For the Ace.1 locus, results were available for 1006 C. pipiens, including 164 resistant (genotype Ace. $1^{R} /$ Ace. $I^{R}$ ) and 290 susceptible (genotype Ace. $I^{S} /$ Ace. $^{S}$ ) homozygotes, and 552 insects with both susceptible and resistant AChE1 (phenotype [RS]). If [RS] mosquitoes were all of the Ace. $I^{R} /$ Ace. $I^{S}$ genotype, there would be a large $\left(\hat{F}_{\text {IS }}=-0.114\right)$ and significant (U-Score test, $P<10^{-5}$ ) excess of heterozygotes. This suggests that the duplicated allele Ace. $1^{R S}$ is present at a substantial frequency (at least 0.059 , if it is assumed that all 
Table 2 Temporal variations in resistance phenotype frequencies in Culex pipiens during periods of different entrance dynamics

\begin{tabular}{|c|c|c|c|c|c|c|c|c|c|}
\hline & \multicolumn{6}{|c|}{ P1 } & & & \\
\hline & \multicolumn{3}{|c|}{$1-20$} & \multicolumn{3}{|c|}{$1-50$} & \multicolumn{3}{|c|}{$\mathrm{P} 2$} \\
\hline & $\% \mathrm{D}$ & Slope & $P$ & $\% \mathrm{D}$ & Slope & $P$ & $\% \mathrm{D}$ & Slope & $P$ \\
\hline \multicolumn{10}{|l|}{ Ester } \\
\hline$[\mathrm{O}]$ & 67.0 & -0.046 & 0.027 & 27.6 & -0.013 & 0.020 & - & - & 0.878 \\
\hline$[4]$ & 36.4 & +0.031 & 0.107 & 22.3 & +0.010 & 0.031 & - & - & 0.781 \\
\hline Other & - & - & 0.560 & - & - & 0.941 & - & - & 0.518 \\
\hline \multicolumn{10}{|l|}{ Ace. 1} \\
\hline [SS] & 56.7 & -0.052 & 0.048 & - & - & 0.577 & 22.7 & +0.013 & 0.100 \\
\hline$[\mathrm{RS}]$ & - & - & 0.599 & - & - & 0.333 & - & - & 0.773 \\
\hline [RR] & 36.3 & +0.0693 & 0.086 & 12.5 & +0.013 & 0.115 & 67.9 & -0.056 & 0.003 \\
\hline $\begin{array}{c}\text { Ester \& Ace.1 } \\
\quad\{\mathrm{S}, \mathrm{O}\}\end{array}$ & 62.4 & -0.075 & 0.019 & 17.1 & -0.012 & 0.141 & - & - & 0.232 \\
\hline
\end{tabular}

Table 3 Estimated rates of entrance (linear estimate) during P2 for Ace.1 resistance phenotypes of Culex pipiens, taking $[\mathrm{SS}]$ as reference

\begin{tabular}{lcccc}
\hline Ace.1 phenotype & Linear estimate & $(\mathrm{SE})$ & Daily survival & $(95 \% \mathrm{CI})$ \\
\hline$[\mathrm{SS}]$ & 0 & - & 1.0 & - \\
{$[\mathrm{RS}]$} & -0.025 & $(0.013)$ & 0.975 & $(0.951-1.000)$ \\
{$[\mathrm{RR}]$} & -0.074 & $(0.025)$ & 0.928 & $(0.884-0.975)$ \\
\hline
\end{tabular}

The corresponding daily survival is indicated. Standard error of the linear estimate and $95 \%$ confidence interval of the daily survival estimates in parentheses. See text for explanations. apparent heterozygote excess is due to the presence of this allele, which is a conservative assumption due to the presence of a Wahlund effect, see below). The two classes of homozygous mosquitoes ([SS] and [RR]) were not randomly distributed through time (Fig. 2B). The frequency of $[\mathrm{SS}]$ mosquitoes decreased significantly $(P=0.048)$ during the first 20 days (Table 2$)$, although this trend was more pronounced during the first 10 days $(P=0.011)$. This effect was possibly counterbalanced by an increase of $[R R]$ mosquitoes, although this trend was marginally not significant (Table 2 ). During the P2 period, there was a significant $(P=0.003)$ decrease of [RR] mosquitoes relatively to [SS] ones. The rate of entry of [RR], [RS] and [SS] mosquitoes explaining this variation in $\mathrm{P} 2$ was computed using a Poisson log-linear model. Introducing a distinct slope for each phenotype had a significant effect on the model $\left(\chi^{2}=12.7\right.$, d.f. $=2$, $P=0.002$ ), and these slopes were used to compute the rate of entry of [RR] and [RS] relative to [SS] (Table 3). Overall, no significant variation was detected between $\mathrm{P} 1$ and $\mathrm{P} 2$ either for the three phenotypic classes $(2 \times 3$
Fisher exact test, $P=0.825$ ) or for all possible pooling $(2 \times 2$ Fisher exact test, $P=0.605, P=0.777$ and $P=1)$.

Data for both resistance loci (Ester and Ace.1) were available for 974 mosquitoes. The frequency of double susceptible $\{\mathrm{S}, 0\}$ mosquitoes decreased significantly during the first 20 days, and the same trend is apparent, although not significant $(P=0.14)$, during the whole P1 period (Table 2). Overall, phenotypic classes at both loci were not randomly associated $(2 \times 2$ Fisher exact test, $\left.P<10^{-5}\right)$, and the linkage disequilibrium between the susceptible alleles $(D=f(\{\mathrm{~S}, 0\})-f([0]) \times f([\mathrm{SS}]))$ was $D=0.037$ overall. This was also true for P1 $\left(P<10^{-5}\right.$, $D=0.034)$ and $\mathrm{P} 2(P=0.004, D=0.083)$. To compute the variation of $D$ through time, consecutive samples were pooled whenever necessary, in order to achieve a minimum sample of 35 mosquitoes for each point. During P1, the disequilibrium apparently decreased, from approximately $0.06-0.00$, although this trend was not significant (Spearman rank-order correlation, $r_{\mathrm{s}}=-0.34, n=16$, one-tailed $P=0.10$ ). The sample size was too low to compute the variation of $D$ during the $\mathrm{P} 2$ period. 


\section{Discussion}

\section{Dynamics of mosquito arrival in cave}

$C$. pipiens females were entering the cave over a fivemonth period through the winter, in large numbers during the first two months (P1 period, $N=1281$ ), and in low, regular numbers later ( $\mathrm{P} 2$ period, $N=107)$.

The 107 C. pipiens females entering the cave during the P2 period cannot represent newly emerged individuals. The most likely hypothesis is that these mosquitoes were coming from other overwintering sites. Such transfer between overwintering sites has been reported for C. pipiens from England, Japan and USA (Ishii et al., 1964; Service, 1968; Hayes, 1973). Thus it could be assumed that P1 corresponds essentially to the first arrival of hibernating females, and $\mathrm{P} 2$ to females moving between overwintering sites.

\section{Insecticide resistance genes during P1}

Susceptible and resistant mosquitoes do not enter the cave at the same time: susceptible mosquitoes enter the cave first, followed by resistant ones, this effect being particularly pronounced during the first 20 days of sampling (Table 2). This could be the expression of a difference between susceptible and resistant mosquitoes, e.g. susceptible mosquitoes seeking an overwintering site earlier than resistant ones (and how this difference is translated into fitness cost or advantage remains unclear). Alternatively, it could represent a migration phenomenon, e.g. mosquitoes from more susceptible local populations starting to overwinter first. The latter assumes that both resistance loci are affected in the same direction, and thus this hypothesis could be rejected only if mosquitoes resistant or susceptible at only one locus entered the cave differentially (or if the pattern were reversed between both loci). The present data clearly show that mosquitoes susceptible at both loci entered the cave first. It is therefore not possible to establish the existence of a fitness difference to explain this variation in arrival date between resistant and susceptible mosquitoes. In addition, the observed pattern (susceptible mosquitoes entering the cave first) is consistent with a temperature gradient of about $3^{\circ} \mathrm{C}$ (see Lenormand \& Raymond, 2000), existing between the treated and the untreated areas. The untreated area is more inland and experiences colder conditions, particularly during October and November when temperatures are decreasing. This is also consistent with the large migration variance $\left(\sigma=14.6 \mathrm{~km} /\right.$ generation $\left.^{-1 / 2}\right)$ estimated at this period in the Montpellier area (Lenormand \& Raymond, 2000), indicating that mosquitoes can fly long distances before entering an overwintering site (the closest untreated areas are less than $10 \mathrm{~km}$ from the focal cave).

In conclusion, the variation in resistance gene frequencies during the first period (P1) is best explained by a migration hypothesis (mosquitoes from more susceptible populations starting to overwinter first), rather than by the expression of a fitness cost. As a consequence, the 1281 C. pipiens mosquitoes captured during the P1 period represent probably a mixture from distant populations along the cline of resistance gene frequencies, explaining the overall significant linkage disequilibrium $(D=0.034)$ between Ace.l and Ester.

\section{Insecticide resistance genes during P2}

Mosquitoes captured during P2 originate from one or several overwintering sites. Why mosquitoes change their overwintering site remains unclear. During winter, the overall overwintering population size of $C$. pipiens undergoes a drastic decrease, to $\approx 10 \%$ of its initial size in the UK (Service, 1968; Sulaiman \& Service, 1983), as well as in southern France (Bourguet, 1996; Guillemaud, 1997; Lenormand, 1998). The quality of each overwintering site, as experienced by a $C$. pipiens female, is probably very different, depending on multiple parameters (such as the inside temperature, humidity level, predator density, parasite frequency, human disturbance, etc.), and this quality probably varies during winter (see, e.g. Berg \& Lang, 1948; Hayes, 1973; Jupp, 1979; Sulaiman \& Service, 1983). Exploring alternative overwintering sites could thus represent an adaptive response.

Mosquitoes newly arriving in a cave during P2 have overcome two possible costs: a survival cost in their original overwintering site, from their first entrance until their decision to leave, and a migration cost associated with the hazardous task of finding an alternative overwintering site.

For Ester, no variation in phenotype frequency is apparent during P2, indicating an absence of a differential survival cost during this period. However, there is a significant difference (from 0.72 to 0.59 ) in resistance phenotypes between P1 and P2 (Fig. 2A). Two distinct types of cost could explain this difference. First a survival cost during P1. Although this cost could not be directly detected in the focal cave, in nearby caves of lower quality, which are probably the sources of mosquitoes caught during P2, such a cost would have reduced the frequency of $\{E\}$ mosquitoes at the end of $\mathrm{P} 1$. Second a migration cost, operating while trying to find an alternative overwintering site. The present experimental setup does not allow us to distinguish between these two possibilities, and we will refer to the 
generic designation of 'survival cost'. The maximum likelihood estimate of this cost is 0.42 . Nevertheless, it cannot be assumed that this overall cost detected at Ester is only due to a migration cost, because an indirect survival cost is probably operating through Ace.l (see below), due to the existing linkage disequilibrium between the two loci.

For Ace.1, a decrease of newly entering resistant phenotypes is observed during $\mathrm{P} 2$, although no significant frequency difference existed between $\mathrm{P} 1$ and $\mathrm{P} 2$. This suggests that a survival cost within some overwintering sites is associated with Ace.1 during P2, estimated to be $\approx 7 \%$ and $2.5 \%$ per day for [RR] and [RS], respectively (Table 3). The estimate for [RS] mosquitoes is marginally not different from zero.

These values are higher than previous estimates obtained for the whole area, over the whole winter (0.26 for Ester and less than 1\% per day for Ace.1 Lenormand et al., 1998b). This suggests that the fitness cost varies either geographically (it is higher in some overwintering sites of poor quality, such as those left by mosquitoes entering the focal cave during P2) or temporally (it is higher between $\mathrm{P} 1$ and $\mathrm{P} 2$ for Ester, and during $\mathrm{P} 2$ for Ace.1).

The proximal causes of these costs are unknown. The survival cost within an overwintering site could be related to differential predation (e.g. by spiders) or parasitism (e.g. by fungi) (Service, 1968; Sulaiman \& Service, 1983; unpublished data), or to the differential exhaustion of lipidic material. No clue is available for the possible migration cost, although its association with resistant phenotypes at Ester suggests that devoting resources to esterase overproduction (instead of something else) is deleterious for such a task. Whatever the real proximal cause of the overwintering cost, the present data suggest that this cost is of a different nature for each resistance locus.

Variation of insecticide resistance gene frequency in the absence of insecticides is not necessarily the expression of a fitness cost. For example, the variation observed during the P1 period is best explained as a population phenomenon, although it would have been interpreted otherwise in the context of a restricted study without the knowledge of the local cline dynamics of resistance genes. The fitness cost is best observed when the quality of the overwintering site is forcing mosquitoes to find an alternative place. As a result, mosquitoes arriving at a new site have a lower frequency of resistance genes, due to the survival cost experienced in the previous site of low quality, or during the switch between overwintering sites. Further studies are required to identify the proximal causes of these fitness costs.

\section{Acknowledgements}

We are very grateful to G. Bertault, C. Berticat, M.-P. Dubois, S. Gourmala, T. Guillemaud, M. Michaud, D. Rey, O. Ronce and F. Rousset for their contribution to the mosquito sampling, C. Berticat and N. Pasteur for helpful comments on the manuscript, F. Rousset for help in statistics, C. Hovette for the authorization to access regularly the cave and to $\mathrm{C}$. Bernard and G. Pistre for technical assistance. This work was financed in part by the PNETOX programme and the AIP 'Génomes et Fonctions' 97/P00183 of INRA. C.C. was supported in part by the Société de Secours des Amis des Sciences. Contribution 01.085 of the Institut des Sciences de l'Evolution de Montpellier (UMR CNRS 5554).

\section{References}

BAKER, R. J. 1987. GLIM 3.77 reference manual. Numerical Algorithms Group, Oxford.

BERG, M. AND LANG, S. 1948. Observations of hibernating mosquitoes in Massachusetts. Mosquito News, 8, 70-71.

BOURGUET, D. 1996. Mécanismes biochimiques, plasticité et évolution de la dominance: l'acétylcholinestérase et la résistance aux insecticides chez le moustique Culex pipiens. Thèse de Doctorat, University of Montpellier II.

BOURGUET, D., CAPELA, R. AND RAYMOND, M. 1996a. An insensitive acetylcholinesterase in Culex pipiens L. mosquitoes from Portugal. J. Econ. Entomol., 89, 1060-1066.

BOURGUET, D., PASTEUR, N., BISSET, J. AND RAYMOND, M. 1996 b. Determination of Ace.l genotypes in single mosquitoes: toward an ecumenical biochemical test. Pest. Biochem. Physiol., 55, 122-128.

BOURGUET, D., RAYMOND, M., FOURNIER, D., MALCOLM, D. ET AL. 1996c. Existence of two acetylcholinesterases in the mosquito Culex pipiens complex (Diptera: Culicidae). J. Neurochem., 67, 2115-2123.

Chevillon, C., Bourguet, D., Rousset, F., PASteur, N. ET AL. 1997. Pleiotropy of adaptive changes in populations: comparisons among insecticide resistance genes in Culex pipiens. Genet. Res., 68, 195-203.

CRAWLEY, M. J. 1993. GLIM for Ecologists. Blackwell Scientific Publications, Oxford.

DAVIES, A. G., GAME, A. Y., CHEN, Z., Williams, T. J. ET AL. 1996. Scalloped wings is the Lucilia cuprima Notch homologue and a candidate for the Modifier of fitness and asymmetry of diazinon resistance. Genetics, 143, 1321-1337.

FISHER, R. A. 1935. The logic of inductive inference. J. R. Stat. Soc., 98, 39-54.

FOSTER, S. P., HARRINGTON, R., DEVONShIRE, A. L., DENHOLM, I. ET AL. 1996. Comparative survival of insecticide-susceptible and resistant peach-potato aphids, Myzus persicae (Sulzer) (Hemiptera: Aphididae), in low temperature field trials. Bull. Entomol. Res., 86, 17-27.

FOSTER, S. P., HARRINGTON, R., DEVONSHIRE, A. L., DENHOLM, I. ET $A L$. 1997. Evidence for a possible fitness trade-off between 
insecticide resistance and the low temperature movement that is essential for survival of UK populations of Myzus persicae (Hemiptera: Aphididae). Bull. Entomol. Res., 87, 573-579.

FOSTER, S. P., DENHOLM, I. AND DEVONSHIRE, A. L. 2000. The ups and downs of insecticide resistance in peach-potato aphids (Myzus persicae) in the UK. Crop Protect., 19, 873-879.

GEORGHIOU, G. P. 1972. The evolution of resistance to pesticides. Ann. Rev. Ecol. Syst., 3, 133-168.

Guillemaud, T. 1997. Etudes de phénomènes sélectifs chez Culex pipiens. Thèse de Doctorat, University of Montpellier II.

GUillemaud, T., MAKATE, N., RAYMOND, M., HIRST, B. ET AL. 1997. Esterase gene amplification in Culex pipiens. Insect Mol. Biol., 6, 319-327.

GUillemaud, T., LENORMAND, T., BOURGUeT, D., CHEVILlon, C. ET AL. 1998. Evolution of resistance in Culex pipiens: allele replacement and changing environment. Evolution, 52, 430-440.

HAYES, J. 1973. Overwinterirng Culex pipiens pipiens in the Ohio-Mississippi river basin 1962-67. Mosquito News, 33, 424-428.

ISHII, T., NAGAI, A., HiRONO, T. AND NAKAMURA, K. 1964. Hibernation of mosquitoes in rock caves on Miyato island. Sci. Rep. Tôhoku Univ. Ser. IV, 30, 159-165.

JUPP, P. G. 1979. Culex (Culex) pipiens and Culex (Cx.) torrentium (Diptera: Culicidae) in England: notes on their taxonomy and biology. Mosquito Syst., 11, 121-126.

LENORMAND, T. 1998. Dynamique de l'adaptation locale: résistance aux insecticides chez Culex pipiens. Thèse de Doctorat, Université de Montpellier II.

LENORMAND, T. AND RAYMOND, M. 2000. Clines with variable selection and variable migration: model and field studies. Am. Nat, 155, 70-82.

LENORMAND, T., GUILLEMAUD, T., BOURGUET, D. AND RAYMOND, M. 1998a. Appearance and sweep of a gene duplication: adaptive response and potential for a new function in the mosquito Culex pipiens. Evolution, 52, 1705-1712.

LENORMAND, T., GUILLEMAUD, T., BOURGUET, D. AND RAYMOND, M. 1998b. Evaluating gene flow using selected markers: a case study. Genetics, 149, 1383-1392.

LENORMAND, T., BOURGUET, D., GUILLEMAUD, T. AND RAYMOND, M. 1999. Tracking the evolution of insecticide resistance in the mosquito Culex pipiens. Nature, 400, 861-864.

MAlColm, C. A., Bourguet, D., ASCOlillo, A., RoOKer, S. J. ET AL. 1998. A sex-linked Ace gene, not linked to insensitive acetylcholinesterase mediated insecticide resistance in Culex pipiens. Insect Mol. Biol., 7, 107-120.

MANLY, B. J. F. 1985. The Statistics of Natural Selection on Animal Populations. Chapman \& Hall, London.
MCKENZIE, J. A. 1994. Selection at the diazinon resistance locus in overwintering populations of Lucilia cuprina (the Australian sheep blowfly). Heredity, 73, 57-64.

ORR, H. A. 1998. The population genetics of adaptation: the distribution of factors fixed during adaptive evolution. Evolution, 52, 935-949.

PASTEUR, N., ISEKI, A. AND GEORGHIOU, G. P. 1981a. Genetic and biochemical studies of the highly active esterases $A^{\prime}$ and $B$ associated with organophosphate resistance in mosquitoes of the Culex pipiens complex. Biochem. Genet., 19, 909-919.

PASTEUR, N., SINĖGRE, G. AND GABINAUD, A. 1981b. Est-2 and Est-3 polymorphism in Culex pipiens L. from southern France in relation to organophosphate resistance. Biochem. Genet., 19, 499-508.

PASTEUR, N., PASTEUR, G., BONHOMME, F. AND BRITTON-DAVIDIAN, J. 1988. Practical Isozyme Genetics. Ellis Horwood Ltd, Chichester, England.

RAYMOND, M. AND ROUSSET, F. 1995. An exact test for population differentiation. Evolution, 49, 1280-1283.

RAYMOND, M., FOURNIER, D., BRIDE, J.-M., CUANY, A. ET AL. 1986. Identification of resistance mechanisms in Culex pipiens (Diptera: Culicidae) from southern France: insensitive acetylcholinesterase and detoxifying oxidases. J. Econ. Entomol., 79, 1452-1458.

ROOKER, S., GUillemaud, T., BerGÉ, J., PASTEUR, N. ET AL. 1996. Coamplification of esterase A and B genes as a single unit in the mosquito Culex pipiens. Heredity, 77, 555-561.

ROUSH, R. T. AND MCKENZIE, J. A. 1987. Ecological studies of insecticide and acaricide resistance. Ann. Rev. Entomol., 32, 361-380.

ROUSSET, F. AND RAYMOND, M. 1995. Testing heterozygote excess and deficiency. Genetics, 140, 1413-1419.

SERVICE, M. W. 1968. Observations on the ecology of some British mosquitoes. Bull. Entomol. Res., 59, 161-194.

DE STORDEUR, E. 1976. Esterases in the mosquito Culex pipiens pipiens L. formal genetics and polymorphism of adult esterases. Biochem. Genet., 14, 481-493.

SUlAimAN, S. AND SERVICE, M. W. 1983. Studies on hibernating populations of the mosquito Culex pipiens L. in southern and northern England. J. Nat. Hist., 17, 849-857.

UYENOYAMA, M. 1986. Pleiotropy and the evolution of genetic systems conferring resistance to pesticides. In: Committee on strategies for the management of pesticide resistant pest populations, (ed.) Pesticide Resistance: Strategies and Tactics for Management, pp. 207-221. National Academy Press, Washington, DC.

WEIR, B. S. AND COCKERHAM, C. C. 1984. Estimating $F$-statistics for the analysis of population structure. Evolution, 38, $1358-1370$. 